\title{
The African buffalo: A villain for inter-species spread of infectious diseases in southern Africa
}

\author{
Authors: \\ Anita L. Michel ${ }^{1}$ \\ Roy G. Bengis ${ }^{2}$ \\ Affiliations: \\ ${ }^{1}$ Department of Veterinary \\ Tropical Diseases, University \\ of Pretoria, South Africa \\ ${ }^{2}$ Directorate Veterinary \\ Services, Skukuza, \\ South Africa \\ Correspondence to: \\ Anita Michel \\ Email: \\ anita.michel@up.ac.za \\ Postal address: \\ Private Bag X04, \\ Onderstepoort 0110, \\ South Africa \\ How to cite this proceeding: \\ Michel, A.L. \& Bengis, \\ R.G., 2012, 'The African \\ buffalo: A villain for inter- \\ species spread of infectious \\ diseases in southern Africa', \\ Onderstepoort Journal of \\ Veterinary Research 79(2), \\ Art. \#453, 5 pages. http:// \\ dx.doi.org/10.4102/ojvr. \\ v79i2.453

\section{Note:} \\ Proceedings of the \\ Conference of the Southern \\ African Centre for Infectious \\ Disease Surveillance 'One \\ Health' held at the National \\ Institute for Communicable \\ Diseases, Johannesburg, July \\ 2011.
}

C) 2012. The Authors. Licensee: AOSIS OpenJournals. This work is licensed under the Creative Commons Attribution License.
The African buffalo (Syncerus caffer) is a large wild bovid which until recently ranged across all but the driest parts of sub-Saharan Africa, and their local range being limited to about $20 \mathrm{~km}$ from surface water. They are of high ecological value due to their important role as bulk feeders in the grazing hierarchy. They also have high economic value, because they are one of the sought after 'Big Five' in the eco-tourism industry. In Africa, buffaloes have been recognised for some time as an important role player in the maintenance and transmission of a variety of economically important livestock diseases at the wildlife and/or livestock interface. These include African strains of foot-and-mouth disease (FMD), Corridor disease (theileriosis), bovine tuberculosis and bovine brucellosis. For a number of other diseases of veterinary importance, African buffaloes may also serve as amplifier or incidental host, whereby infection with the causative pathogens may cause severe clinical signs such as death or abortion as in the case of anthrax and Rift Valley fever, or remain mild or subclinical for example heartwater. The long term health implications of most of those infections on the buffalo at a population level is usually limited, and they do not pose a threat on the population's survival. Because of their ability to harbour and transmit important diseases to livestock, their sustainable future in ecotourism, trade and transfrontier conservation projects become complex and costly and reliable diagnostic tools are required to monitor these infections in buffalo populations.

\section{Introduction}

The transmission and spread of infectious diseases amongst and between domestic and wild animals can occur directly through contact (foot-and-mouth disease [FMD], bovine tuberculosis and brucellosis), or indirectly through the agency of haematophagous arthropod vectors such as mosquitoes, tsetse flies and Ixodid ticks (Kock 2005). In addition, environmental contamination with infected ticks (theileriosis) or fomites (anthrax) can infect livestock even when the habitat is not shared at the same time. Some of these diseases can affect a variety of wildlife hosts, but only very few species play a decisive role in disease maintenance and transmission at the wildlife and/or livestock interface. The increasing competition for land available for livestock - based agriculture or wildlife ranching and conservation has highlighted the need for an integrated approach to sustainable livestock and wildlife health, use and management. In this debate the African buffalo features as a villain to those who wish to protect livestock populations from devastating diseases, as they undermine national and international disease eradication schemes, which have been implemented and executed with significant success, and at great cost in the past (Munag'andu et al. 2006). On the other hand, conservationists and wildlife ranchers take on a distinctly different attitude towards controlling livestock diseases transmitted by wildlife (Bengis, Kock \& Fischer 2002).

In this overview the role of the African buffalo, both as a victim and asymptomatic carrier in the transmission of the most important livestock diseases at the wildlife and/or livestock interface, is reviewed. Links between disease ecology and buffaloes' ecology are examined in an attempt to reveal why buffaloes are successful maintenance hosts for several of those diseases.

\section{Status of African buffaloes}

Since the early days of European settlement in southern and eastern Africa, African buffaloes have attracted the admiration of hunters and have consequently been a highly sought after trophy animal for the past three centuries (Prins 1996). In addition, they gained extraordinary value for other ecotourism related purposes during the past decades (Van der Merwe, Saayman \& Krugell 2004). The African buffalo (Syncerus caffer) is one of the most ubiquitous large herbivores which can tolerate a wide range of climatic conditions and habitats as long as it is provided with access to an abundant supply of water (Grimsdell 1969; Sinclair 1977). Ecologically, the African buffalo is a bulk grazer and occupies an important niche through opening up habitats that are preferred by short-grass grazers (De Vos \& Bengis 1994). Currently the conservation status of the African 
buffalo is satisfactory with no immediate threat of extinction (Friedmann \& Daly 2004).

\section{Infectious diseases transmitted by African buffaloes}

African buffaloes have been recognised for some time for various roles in disease transmission amongst wildlife species and at the interface with livestock. Amongst the best known diseases are foot-and-mouth disease, caused by the African strains SAT 1, 2 and 3 (FMD viruses) and Corridor disease (theileriosis, caused by Theileria parva), owing to the disastrous, large scale clinical outbreaks they may cause in livestock (Anonymous 2007; Norval, Perry \& Young 1992). However, African buffaloes have been implicated in a number of other epidemiological roles involving both indigenous and alien livestock diseases.

Diseases which originated in Africa and co-evolved with African wildlife species including African buffaloes are defined as indigenous. They generally do not pose a threat on the survival of their hosts' populations because of the evolutionary development of unique coping mechanisms. Well known indigenous diseases maintained by African buffaloes include FMD caused by the SAT strain viruses (Thomson 1995), Corridor disease and African trypanosomosis (Anonymous 2007, 2009; De Vos \& Bengis 1994; Norval et al. 1992).

In contrast, foreign, so-called alien livestock diseases, such as bovine tuberculosis (Mycobacterium bovis) and bovine brucellosis (Brucella abortus), have been introduced and successfully established themselves in buffaloes which serve as wildlife maintenance host (De Vos et al. 2001). Rinderpest falls within the same grouping of alien diseases but its extreme pathogenicity and high mortality precluded the development of a wildlife reservoir (De Vos \& Bengis 1994). The devastating effect of rinderpest on many cloven hoofed African ungulate species and African buffaloes (as an epidemic end host) in particular at a local or regional population level was more important ecologically and epidemiologically than their potential role in transmission of the disease to livestock. In 2011, rinderpest was officially eradicated from the world (Morens et al. 2011) and therefore its significance for interspecies transmission no longer exists.

Due to their wide geographical range and distribution, African buffaloes have been furthermore implicated as amplifiers or incidental hosts in the epidemiology of a number of other indigenous infectious agents, including those confined to specific localised geographic areas, for example trypanosomes is limited to certain savannah and forested areas endemic for tsetse flies, and buffalo are one of the preferred hosts for these flies and develop a symptomatic carrier state for this parasite (Molooa et al. 1999).

Anthrax, caused by Brucella anthracis is limited to certain anthrax endemic areas of the African continent (Anonymous 2009). For Rift Valley fever little is known about the precise mechanisms of virus maintenance and transmission. However, buffaloes have been associated with a possible sentinel role during epidemics and a possible maintenance role during interepidemic periods, respectively (Bengis et al. 2010; LaBeaud et al. 2011).

\section{Factors related to African buffaloes in disease transmission}

The epidemiology of infectious diseases is determined by factors related to the host, the environment and the causative pathogen. In the case of African buffaloes a number of intrinsic behavioural characteristics are instrumental to its role in hosting and transmitting livestock diseases. They are a highly social species living in large herds of up to 1000 animals, whose gregarious behaviour provides ideal conditions for direct pathogen transmission via aerosol and body secretions (Grimsdell 1969; Michel et al. 2006). Individual or small groups of buffaloes have also been shown to migrate over large distances within short periods of time, either in response to drought or as a result of the dispersal strategies for heifers or bachelor bulls. These events, like fission and fusion events driven by changes in the seasonal availability of grazing, take place on a regular basis and constitute a powerful vehicle for pathogen dispersal across herds (Cross, Lloyd-Smith \& Getz 2005; Halley, Vandewalle \& Taolo 2002).

\section{Factors related to the pathogen}

As regards the chronic, slow alien livestock diseases, such as bovine tuberculosis and bovine brucellosis, the lack of coping mechanisms in naïve African buffaloes may result in deleterious long term effect on certain buffalo populations.

Some pathogens exhibit a very strict and narrow host range, for example T. parva, whilst M. bovis is capable of causing disease in a very broad spectrum of domestic and wild animal species. Amongst its wildlife hosts, maintenance host potential has been confirmed for African buffaloes and is suspected for greater kudu and possibly others (Michel et al. 2006). Indirect transmission of pathogens via environmental contamination is more effective if the organism can survive for significant periods of time outside of its host(s). Whilst the survival of most viruses outside the host is very short, M. bovis has been shown to survive for between five days and four weeks in the environment (Tanner \& Michel 1999) and the spore forming Bacillus anthracis bacterium is ideally equipped for long term (years) survival outside of a host (De Vos 2004).

\section{Factors related to the environment}

African buffaloes occur in many different habitats including woodlands, grasslands, swamps, floodplains and thickets, at a range of altitudes, provided they have access to an abundant supply of water and good quality grazing. This species' ability to survive in all but the more arid habitats, allows it to host a variety of pathogens under diverse environmental conditions. For example, the abundance of 
the Aedine mosquitoes, the endemic vector of the Rift Valley fever virus, is influenced by wet climatic shifts which are frequently associated with increased virus transmission to domestic and wild ruminants (Bengis et al. 2010). In addition, African buffaloes spend a considerable percentage of their time in and near water (Ryan, Knechtel \& Getz 2006) which further increases their risk of exposure to vectors. In addition, African buffaloes are a preferred host for certain ixodid tick species, the vectors of various protozoal and rickettsial parasites of bovids.

The modern wildlife industry grows at an average annual rate of $5.6 \%$ in terms of area exempted for game ranching and is mainly based on ecotourism, hunting and live game trade (Cloete, Taljaard \& Grove 2007). This rapid growth rate in conjunction with the historical iconic role of the African buffalo as a member of the 'Big Five' for viewing, photographing and hunting has lead to an increase in the numbers and distribution of buffaloes on private land. In certain parts of South Africa the number of game farms registered for keeping buffaloes has equalled or exceeded that of livestock, resulting in an expansion of the wildlife and/or live stock interface and hence a risk in bi-directional disease transmission. High population densities and frequent translocation of African buffaloes between private game properties for commercial gain are contributing to cumulative risk of African buffalo to contract or transmit livestock diseases. For this reason, in South Africa buffaloes and cattle may not be kept together on shared rangeland. However, pathogens do not generally respect fences.

Against the background of the establishment of large wildlife conservation areas and transfrontier parks in southern Africa, the potential role of buffaloes in the transmission of infectious diseases at the wildlife and/or livestock interface cannot be ignored. High expectations have been linked to the creation of large conservation areas in terms of improved and sustainable livelihoods for the communities in and around those wildlife areas. However, increased numbers of livestock and buffaloes, in the absence of game deterrent fences and often a lack of effective livestock vaccines, will inevitably increase the risk of disease transmission, and make disease eradication from livestock virtually impossible (Kock 2005).

\section{Impact of infectious diseases on African buffaloes and their environment}

Amongst the infectious diseases, FMD and Corridor disease and African trypanosomosis are truly asymptomatic in African buffaloes, which act as biological reservoirs of infection in an endemic cycle. The FMD infection occasionally escapes into other sympatric wild cloven-hoofed species, and where livestock are in contact with African buffaloes, they may become infected resulting in devastating outbreaks with a high socio-economic impact (Vosloo et al. 2005).

Rift Valley fever, is a seasonal vector born disease and viremia and abortions have been reported in African buffaloes (Evans et al. 2008). Their exact role in the epidemiology of Rift Valley fever is however, still unknown but results of serological investigations in Kenya and South Africa indicated that African buffaloes become infected with the virus (Evans et al. 2008; LaBeaud et al. 2011).

Bovine tuberculosis in African buffaloes has been well documented and can be described as a chronic, progressively debilitating condition (De Vos et al. 2001). It has spread throughout the buffalo population of the Kruger National Park and spilled into more than a dozen other wildlife species. There is a continuous risk for spillback into livestock and an associated zoonotic risk for animal owners, which is undetermined (Berg et al. 2011; Michel, Müller \& Van Helden 2010).

Anthrax is a sporadic, usually fatal disease affecting buffaloes in numerous endemic areas in sub-Saharan Africa (De Vos 1990; Mohan \& Gotts 1970). Herbivores are known to be more susceptible to anthrax than omnivores and carnivores, and losses in African buffaloes, greater kudu, nyala and waterbuck have been significant in outbreaks of this disease in southern and eastern Africa (De Vos 2004). When buffaloes are affected by anthrax, they serve as highly effective multipliers of $B$. anthracis, which can contaminate the soil and run-off water, and carcasses become amplifiers for blowflies. Anthrax may be transmitted to neighbouring livestock farms and initiate an outbreak amongst cattle, and the converse has also been experienced when an outbreak in cattle spilled over into wildlife in an adjoining conservation area (Malilangwe - Zimbabwe) (De Vos 1990).

It has been speculated that African buffaloes are the species with the highest susceptibility to rinderpest, which decimated the buffalo populations all over Africa during the rinderpest epidemic between 1888 and 1899 (De Vos \& Bengis 1994).

\section{Diagnosis and control of infectious diseases in African buffaloes}

Availability of diagnostic tests for wildlife species is very often the biggest limitation in diagnosing infectious diseases in target wild life species which are taxonomically far removed from the closest livestock counterparts. The African buffalo falls into the subfamily Bovinae together with domestic cattle, which is helpful and provides a basis for adapting and developing diagnostic tests for relevant infections in buffaloes. However, it needs to be emphasised that all tests applied in buffaloes still require validation to prove fitness for purpose as stated by the World Organisation for Animal Health (OIE) (OIE 2009). The question whether infectious diseases in buffaloes require controlling is a contentious one and is best discussed per disease grouping. Since the causative agents of certain indigenous diseases, namely FMD viruses, trypanosomes and theilerias, are widely maintained by African buffaloes and generally do not pose a threat to these population's existence, diagnostic testing is usually applied for monitoring and surveillance activities at population level. For movement purposes and international 
trade, the same tests (including direct pathogen detection for Corridor disease and trypanosomosis) are applied at individual animal level in conjunction with herd testing records. It is accepted that FMD can at best be contained in wildlife areas that have buffaloes, but eradication will not be achievable (Vosloo et al. 2005).

The situation is essentially the same for indigenous diseases detected less frequently in African buffaloes, such as Rift Valley fever and anthrax, where outbreaks are monitored strictly for epidemiological information and analyses.

A very different scenario is presented in the cases of bovine tuberculosis and bovine brucellosis, which are both alien diseases introduced into the buffalo population most likely through contact with infected cattle. Following their successful establishment in African buffaloes as their wildlife reservoir or maintenance host, the state veterinary and conservation authorities have been faced with a set of previously unknown challenges. Apart from the need to prevent spillover of the diseases to neighbouring livestock, these diseases may spread uncontrolled within infected conservation areas. Although our current knowledge on the impact of bovine tuberculosis and bovine brucellosis does not indicate an immediate threat on buffalo survival at the population level, it would be premature to make any prediction about the long term impact at this point in time. As no effective vaccine exists for bovine tuberculosis in animals and given the extremely broad host spectrum of the causative organism, the real threat goes beyond buffalo conservation but concerns severely affected sympatric species such as lions and kudus (Michel et al. 2009). It is fair to speculate that African buffaloes will not remain the only maintenance host in an endemically infected ecosystem such as the Kruger National Park and disease management and control strategies are urgently called for. Two effective vaccines are registered for the control of bovine brucellosis in cattle, but their efficacy and safety in African buffaloes has not been tested, as the disease is currently considered to have little effect on African buffaloes and the ecosystem (Godfroid 2004). Pre-movement testing of buffaloes for both bovine tuberculosis and brucellosis is an absolute requirement to minimise the risk of disease transmission to uninfected populations. In the case of bovine tuberculosis serological tests are not useful to detect infection and the intradermal tuberculin test (skin test) is applied in conjunction with the interferon gamma assay (Michel et al. 2011; Michel \& Simoes 2009).

\section{Conclusion}

It is clear that disease transmission at the interface is bidirectional and African buffaloes are culprits or villains in respect of some diseases, whilst they have fallen victim to alien diseases transmitted from cattle. As the wildlife and/or livestock and/or human interface is rapidly expanding and gaining in intensity and complexity, there should be no room for a blaming game, but it must be appreciated that African buffaloes form an integral part of the indigenous fauna of Africa and are inseparable from their indigenous pathogens. A strictly separate approach is needed for the alien diseases which may directly affect the health of buffaloes or indirectly the conservation of wildlife by turning infected areas into 'conservation islands' and making them unavailable for conservation in the bigger sense.

To enable ecologists, veterinary researchers and conservation biologists to correctly assess and predict the long term dynamics of significant livestock diseases at this growing and intensifying disease interface, an understanding of the host-parasite interactions at population level in cattle and African buffaloes is crucial to finding solutions and to attempt achieve compatibility between traditional livestock farming and wildlife conservation-based ecotourism. It should also be emphasised that host-parasite interactions are not limited to the processes guiding infection and immunopathogenesis, but they must include the external determinants of the environment, including climate change, human interventions and other ecosystem drivers.

\section{References}

Anonymous, 2007, 'Institutional strategies and economic impacts of alternative FMD prevention and control strategies in Southern Africa', in B.D. Perry \& K.R. Sones (eds.), International Livestock Research Institute, p. 56, Nairobi, Kenya.

Anonymous, 2009, 'African animal trypanosomiasis', Center for Food Security and Public Health, lowa State University, lowa.

Bengis, R.G., Kock, R.A. \& Fischer, J., 2002, 'Infectious animal diseases: The wildlife/ livestock interface', Revue Scientifique et Technique 21, 53-65.

Bengis, R.G., Swanepoel, R., De Klerk, L-M., Pienaar, N.J. \& Prinsloo, G., 2010, 'Rift Valley fever: Current concepts and recent findings', paper presented at the 9th Annual Conference of the 'Southern African Society for Veterinary Epidemiology and Preventive Medicine', The Farm Inn, Pretoria, South Africa, 18-20 August.

Berg, S., Garcia-Pelayo, M., Müller, B., Hailu, E., Asiimwe, B., Kremer, K. et al., 2011 'African 2, a clonal complex of Mycobacterium bovis epidemiologically important in East Africa', Journal of Bacteriology 193, 670-678. http://dx.doi.org/10.1128/ JB.00750-10, PMid:21097608

Cloete, P.C., Taljaard, P.R. \& Grove, B., 2007, 'A comparative economic case study of switching from cattle farming to game ranching in the Northern Cape Province', South African Journal of Wildlife Research 37, 71-78. http://dx.doi. org/10.3957/0379-4369-37.1.71

Cross, P.C., Lloyd-Smith, J.O. \& Getz, W.M., 2005, 'Disentangling association patterns in fission-fusion societies using African buffalo as an example', Animal Behaviour 69, 499-506. http://dx.doi.org/10.1016/j.anbehav.2004.08.006

De Vos, V., 2004, 'Anthrax', in J.A.W Coetzer \& R.C Tustin (eds.), Infectious diseases of livestock, n.p., Oxford University Press, Cape Town.

De Vos, V., 1990, 'The ecology of anthrax in the Kruger National Park, South Africa', Salisbury Medical Bulletin 68, 19-23.

De Vos, V., Bengis, R.G., Kriek, N.P., Michel, A., Keet, D.F., Raath, J.P. \& Huchzermeyer, H.F., 2001, 'The epidemiology of tuberculosis in free-ranging African buffalo (Syncerus caffer) in the Kruger National Park, South Africa', Onderstepoort Journa of Veterinary Research 68, 119-130. PMid:11585089

De Vos, V. \& Bengis, R.G., 1994, 'The disease status of African buffalo in South Africa', in W. Van Hoven, H. Ebedes \& A. Conroy (eds.), Wildlife ranching: A celebration of diversity Proceedings of the 3rd International Wildlife Ranching Symposium Centre for Wildlife Management, University of Pretoria, Pretoria, October, 1992, n.p.

Evans, A., Gakuya, F., Paweska, J.T., Rostal, M., Akoolo, L., Vuren, P.J. et al., 2008 'Prevalence of antibodies against Rift Valley fever virus in Kenyan wildlife', Epidemiology and Infection 136, 1261-1269. http://dx.doi.org/10.1017/ S0950268807009806

Friedmann, Y. \& Daly, B., 2004, Red Data book of mammals of South Africa: A conservation assessment, Conservation Breeding Specialist Group Southern Africa, South Africa.

Godfroid, J., 2004, 'Brucellosis in wildlife', in J.A.W. Coetzer \& R.C. Tustin (eds.), Infectious Diseases of Livestock, Oxford University Press.

Grimsdell, J.J.R., 1969, 'Ecology of the buffalo, Syncerus caffer in western Uganda', $\mathrm{PhD}$ thesis, Cambridge University.

Halley, D.J., Vandewalle, M.E.J. \& Taolo, C., 2002, 'Herd-switching and long-distance dispersal in female African buffalo (Syncerus caffer)', African Journal of Ecology 40 , 97-99. http://dx.doi.org/10.1046/j.0141-6707.2001.00336.x 
Kock, R.A., 2005, 'What is the infamous wildlife/livestock disease interface? A review of current knowledge', Southern and East African Experts Panel on Designing
Successful Conservation and Development Interventions at the Wildlife/Livestock Interface: Implications for Wildlife, Livestock, and Human Health. AHEAD Animal Health for the Environment And Development Forum. IUCN/SSC Veterinary Health for the Environment And Development Forum. IUCN/SSC Veterinary
Specialist Group, Southern Africa Sustainable Use Specialist Group et al., IUCN, Specialist Group, Southern Africa Sustainable Use Specialist Group
Gland, Switzerland and Cambridge, UK, 14-15 September 2003.

LaBeaud, A.D., Cross, P.C., Getz, W.M., Glinka, A. \& King, C.H., 2011, 'Rift Valley fever virus infection in African buffalo (Syncerus caffer) herds in rural South Africa: Evidence of interepidemic transmission', American Journal of Tropical Medicine and Hygiene 84, 641-646. http://dx.doi.org/10.4269/ajtmh.2011.10-0187, PMid:21460024

Michel, A.L., Bengis, R.G., Keet, D.F., Hofmeyr, M., De Klerk, L.-M., Cross, P.C. et al. 2006, 'Wildlife tuberculosis in South African conservation areas: Implications and challenges', Veterinary Microbiology 112, 91-100. http://dx.doi.org/10.1016/j. vetmic.2005.11.035, PMid:16343819

Michel, A.L., Coetzee, M.L., Keet, D.F., Mare, L., Warren, R., Cooper, D. et al., 2009 'Molecular epidemiology of Mycobacterium bovis isolates from free-ranging wildlife in South African game reserves', Veterinary Microbiology
http://dx.doi.org/10.1016/j.vetmic.2008.07.023, PMid:18786785

Michel, A.L., Cooper, D., Jooste, J., De Klerk, L.-M. \& Jolles, A., 2011, 'Approaches towards optimising the gamma interferon assay for diagnosing Mycobacterium bovis infection in African buffalo (Syncerus caffer)', Preventive Veterinary Medicine 98, 142-151. http://dx.doi.org/10.1016/j.prevetmed.2010.10.016, PMid:21122932

Michel, A.L., Müller, B. \& Van Helden, P.D., 2010, 'Mycobacterium bovis at the animalhuman interface: a problem, or not?', Veterinary Microbiology 140, 371-381. $\mathrm{http}: / /$ dx.doi.org/10.1016/j.vetmic.2009.08.029, PMid:19773134

Michel, A.L. \& Simoes, M., 2009, 'Comparative field evaluation of two rapid immunochromatographic tests for the diagnosis of bovine tuberculosis in African buffaloes (Syncerus caffer)', Veterinary Immunology and Immunopathology 127,

Mohan, R.N. \& Gotts, M.G., 1970, 'Diseases and parasites of the African buffalo (Syncerus caffer)', Veterinary Bulletin 40, 157-166.

Molooa, S.K., Orindab, G.O., Sabwaa, C.L., Minjaa, S.H. \& Masakea, R.A., 1999, 'Study on the sequential tsetse-transmitted Trypanosoma congolense, T. brucei bruce and T. vivax infections to African buffalo, eland, waterbuck, N'Dama and Boran cattle', Veterinary Parasitology 80, 197-213. PMid:9950344
Morens, D.M., Holmes, E.C., Davis, A.S. \& Taubenberger, J.K., 2011, ‘Global rinderpest eradication: lessons learned and why humans should celebrate too', Journal of Infectious Diseases 204, 502-505. http://dx.doi.org/10.1093/infdis/jir327, PMid:21653230

Munag'andu, H.M., Siamudaala, V.M., Nambota, A., Bwalya, J.M., Munyeme, M. Mweene, A.S. et al., 2006, 'Disease constraints for utilization of the African buffalo (Syncerus caffer) on game ranches in Zambia', Japanese Journal of Veterinary (Syncerus caffer) on game ranches
Research 54, 3-13. PMid:16786973

Norval, R.A.I., Perry, B.D. \& Young, A.S. (eds.), 1992, The epidemiology of theileriosis in Africa, American Press, London.

OIE, 2009, 'Standard Operating Procedure (SOP) for OIE Validation and Certification of Diagnostic Assays', Version 2.1

Prins, H.H.T., 1996, 'Ecology and behaviour of the African buffalo - Social inequality and decision making', PhD thesis, Chapman \& Hall, London.

Ryan, S.J., Knechtel, C.U. \& Getz, W.M., 2006, 'Range and habitat selection of African buffalo in South Africa', Journal of Wildlife Management 70, 764-776. http:// dx.doi.org/10.2193/0022-541X(2006)70[764:RAHSOA]2.0.CO;2

Sinclair, A.R.E., 1977, 'The African buffalo - a study of resource limitations of populations', PhD thesis, University of Chicago Press.

Tanner, M. \& Michel, A.L., 1999, 'Investigation of the viability of Mycobacterium bovis under different environmental conditions in the Kruger National Park', Onderstepoort Journal of Veterinary Research 66, 185-190. PMid:10631708

Thomson, G.R., 1995, 'Overview of foot and mouth disease in southern Africa', Revue Scientifique et Technique 14, 503-520. PMid:8593386

Van der Merwe, P., Saayman, M. \& Krugell, W., 2004, 'Factors that determine the price of game', Koedoe 47, 105-113.

Vosloo, W., Bastos, A.D.S., Sahle, M., Sangare, O. \& Dwarka, R.M., 2005, 'Virus topotypes and the role of wildlife in foot and mouth disease in Africa', Southern and East African Experts Panel on Designing Successful Conservation and Development Interventions at the Wildlife/Livestock Interface: Implications for Wildlife, Livestock, and Human Health. AHEAD Animal Health for the Environment Wildlife, Livestock, and Human Health. AHEAD Animal Health for the Environment Sustainable Use Specialist Group et al., IUCN, Gland, Switzerland and Cambridge, UK, 14-15 September 2003. 